\title{
Investigating the Effect of the Ribs Spacing on the One Way Reinforced Concrete Ribbed Slab Strength
}

\author{
M. Al-Nasra, R. Abdulraziq, Y. Abouelnaga, A. AlMofleh, O. Ayub, \\ M. Abdelsadig and O. Mohammed \\ School of Engineering, American University of Ras Al Khaimah (AURAK), \\ Ras Al Jaima, United Arab Emirates, \\ Email: moayyad.alnasra@aurak.ac.ae
}

\begin{abstract}
The one way ribbed slab is very common reinforced concrete slab. It considered one of the main structural element in reinforced concrete structures. The main function of these slabs is to carry surface loads efficiently and in many cases to provide higher insulation value. It is common practice to fill the spacing between the ribs with different lightweight materials including cavity concrete blocks and polystyrene foam. This study focused on the spacing between the ribs. The main objective is to study the effect of the ribs spacing on the performance of the one way reinforced concrete ribbed slabs. The other parameters are kept the same for all of the tested samples including the overall thickness, the concrete mix design and the embedded steel reinforcement. Five slabs were prepared and tested by one way flexural bending stress. Polystyrene foam blocks of variable width is used to fill the space between the ribs. The height of the polystyrene foam blocks is kept constant. Special fiber is added to the concrete mix design to improve the performance of the concrete. Parametric study is conducted relating the slab strength with many factors including the material cost and the overall slab weight.
\end{abstract}

Key words: Ribbed slab, ribs spacing, fiber concrete, flexural strength, lightweight materials, reinforcement

\section{INTRODUCTION}

Little research is devoted to study the performance of the one way ribbed slabs. The one way reinforced concrete ribbed slab is very common type of reinforced concrete slabs that has been proven to be effective and easy to build. Concrete blocks of variable width and height are often used in the one way reinforced concrete ribbed slabs. The dimensions of these blocks vary. The function of these concrete blocks is to fill the space between the ribs and to provide heat and sound insulation. The main disadvantage of these blocks is the additional dead weight they add to ribbed slabs. The bonding between the ribbed slabs and these blocks is also a serious issue in case, if these ribbed slabs subjected to dynamic or seismic loading. This poses safety issue for the occupants of these buildings.

Polystyrene foam blocks are viable replacement of these concrete blocks. They are of lighter weight and provide better insulation. The polystyrene foam blocks also come with different sizes depending on the design of the ribbed slabs. The main disadvantage of these blocks is the constructability at the construction sites. In this study polystyrene foam blocks of constant height is used for all of the tested slabs. The width of the polystyrene blacks varies from $0.0-40.0 \mathrm{~cm}$ (0.0-16.0 inch).

Several researchers studied the flexural performance of steel fiber reinforced concrete ribbed slabs with various topping thickness. Studies showed that the performance of the ribbed slabs of $50 \mathrm{~mm}$ ( 2 inch) topping thickness is similar to the performance of the slabs of $75 \mathrm{~mm}$ ( $3.0 \mathrm{inch}$ ) and $100 \mathrm{~mm}$ (4.0 inch) topping thickness (Rahman et al., 2017). Other researchers researched on the optimization of flexural prediction for ribbed floors in bending, shear and deflection. The major conclusion supports the concept of finding an optimum and minimum slab cost provided slab dimensions and material strengths (Abejide and Konitufe, 2015).

The span length is a major factor in the design of reinforced concrete ribbed slabs. The slabs are subjected to many types of stresses including flexural, shear and torsional stresses. The design of the ribbed slabs takes into account all of these stresses (Al-Nasra and Wang, 1994). This may call for an increase in the thickness of the slab and/or add more strength to the slab by providing additional steel reinforcement. Al-Nasra et al. (1926) studied the design of slabs subjected to high value of

Corresponding Author: M. Al-Nasra, School of Engineering, American University of Ras Al Khaimah (AURAK), Ras Al Jaima, United Arab Emirates, Email: moayyad.alnasra@aurak.ac.ae 
shear. New and effective of additional steel reinforced is introduced called swimmer bars. These bars are designed to take care of the high shear values in slabs (Al-Nasra et al., 2013).

The slab performance can be improved by changing the shape of the slab profile. This can be accomplished by providing a slight rise at the center of the slab (Al-Nasra and Daoud 2015, 2016). Adding few centimetres in the rise at the center of the slab improves the flexural strength of the slab and makes the slab shift its behaviour toward shell and away from flat slab.

Extensive study is also conducted on the optimization design of two way ribbed slabs or what is called waffle slabs (Galeb and Atiyah, 2011). The main conclusion of these rigorous studies is that the center to center of ribs spacing is found to be $(6.57-14.76 \%)$ of the total span length in order to get the optimum overall total cost of the waffle slab built with solid heads. Also, the study showed that center to center spacing between ribs is (8.22-16.23\%) of the total span length for optimum and effective design of waffle slabs built with perimeter beams.

Research significance: This research provides answers about the most appropriate center to center spacing between the ribs in one way reinforced concrete ribbed slabs. The research also provides important relationships between the strength of one way reinforced concrete ribbed slabs and the ribs spacing. Also, this study relates the ribs spacing with the strength to weight ratio. The study covers the material cost of the one way ribbed slab as a function of the slab strength.

Experimental investigation: Several $15 \mathrm{~cm}$ (6.0 inch) cubes were prepared to test the concrete in compression. The concrete mix design is kept constant for all of the tested samples. The 9 cubes were tested in compression to determine the average compressive strength of the plain concrete. These cubes were casted, cured and tested in 7 days. The average strength of these cubes is 22.2 $\operatorname{MPa}(3.2 \mathrm{ksi})$.

\section{MATERIALS AND METHODS}

The concrete mix design used in this study is selected for moderate strength concrete and is kept the same for all of the tested slabs and cubes. Table 1 shows the mix design used. Additional fiber is used to improve the concrete performance in ribbed slabs. The water cement ratio is also kept constant at 0.45 . Figure 1 shows the special fiber used in this study. The fiber is of $1 \mathrm{~cm}$ (0.4 inch) length.
Table 1: Concrete ingredient used in this study

\begin{tabular}{lcl}
\hline Ingredient & Weight $(\mathrm{kg})$ & $\mathrm{lb}$ \\
\hline Cement & 11 & 24.25 \\
Fine aggregates & 21 & 46.29 \\
Course aggregates & 30 & 66.14 \\
Water & 5 & 11.02 \\
\hline
\end{tabular}

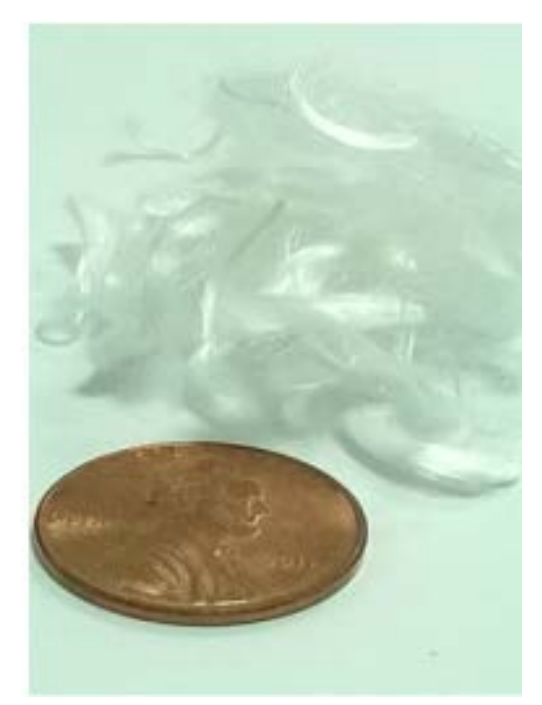

Fig. 1: Fiber used in this study

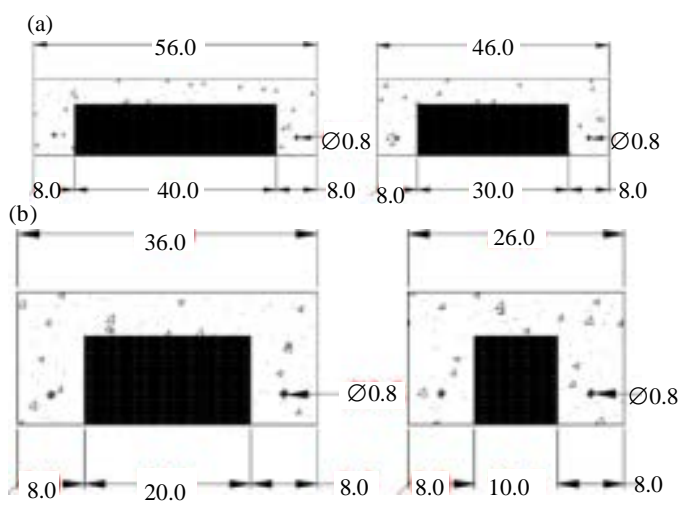

Fig. 2: a, b) Slabs cross-sectional dimensions

Specimens: Several molds for slabs were also prepared to study the effect of the ribs spacing on the performance of the one way slabs. Figure 2 shows the cross sections of the slabs used in this study. The spacing between the ribs is increased by $10 \mathrm{~cm}(4 \mathrm{inch})$ increment. The first slab is solid slab with $0.0 \mathrm{~cm}(0.0$ inch) spacing between the ribs. The slab top thickness is kept constant at $5.0 \mathrm{~cm}$ (2.0 inch). The cross sectional dimensions of the polystyrene blocks varies as follows; $10 \times 10 \mathrm{~cm}(4 \times 4$ inch), $20 \times 10 \mathrm{~cm}(8 \times 4$ inch $), 30 \times 10 \mathrm{~cm}(12 \times 4$ inch $)$ and $40 \times 10 \mathrm{~cm}$ $(16 \times 4$ inch). The length of each slab is also kept constant at $75 \mathrm{~cm}$ ( $30 \mathrm{inch}$ ). The concrete cover at the beginning of the slab and at the end of the slab is also kept constant at 


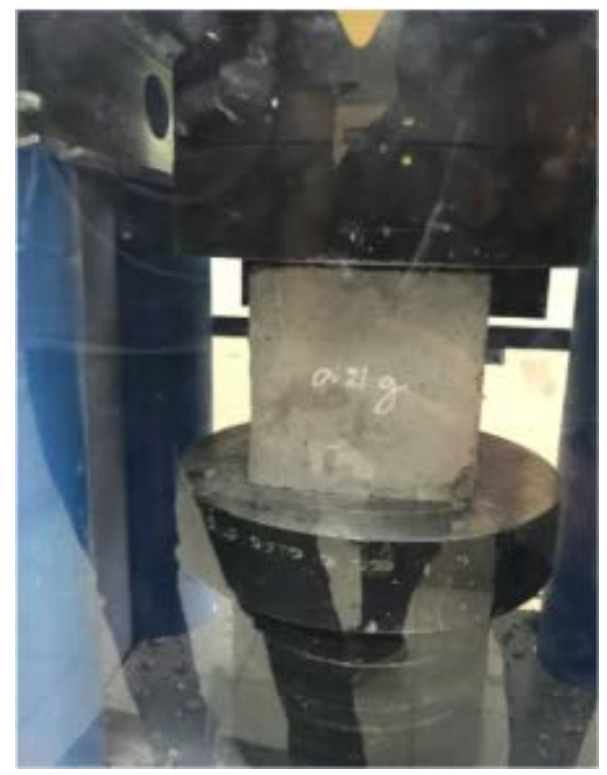

Fig. 3: Concrete cube is tested for compressive strength

$8 \mathrm{~cm}$ (3.2 inch). Two steel reinforcing bars are used as shown in Fig. 2. These two bars are of $8 \mathrm{~mm}(0.32 \mathrm{inch})$ in diameter. The location of these bars is at the middle of each rib $4 \mathrm{~cm}$ ( $1.6 \mathrm{inch}$ ) from either side of the rib and $5 \mathrm{~cm}$ ( 2 inch) from the bottom of the ribs. The width of each rib in every slab used in this study is kept the same of $8 \mathrm{~cm}$ (3.2 inch). The 5 th slab used in this study is of $16 \mathrm{~cm}$ (6.4 inch) in width, $15 \mathrm{~cm}$ (6 inch) in depth and $75 \mathrm{~cm}$ (30 inch) in length reinforced with two reinforcing steel bars of $8 \mathrm{~mm}$ in diameter.

Items of investigation: The concrete compressive strength is measured in this study. Figure 3 shows $15 \mathrm{~cm}$ ( 6 inch) in side length cubes tested in compression. Three different amounts of special fiber is used in this study to find out the best amount to be used that gives the highest strength. The amount of fiber used in this study is expressed in terms of the weight of cement as percentage. The three values used in this study are 0.016, 0.024 and $0.057 \%$ of cement weight. The best performance was at $0.057 \%$. This percentage is used in the concrete mix.

Figure 4 shows illustration of the experimental set up of the tested slabs. Two linear loads are applied at one third of the distance between the supports. The distance between the supports is taken as $45 \mathrm{~cm}$ (18 inch). The linear loads are gradually increased until total flexural failure occur. Figure 5 shows the experimental set up of the tested ribbed slabs.

Analytical investigation: The mode of failure of the slabs is flexural failure initiated by flexural tensile crack at the

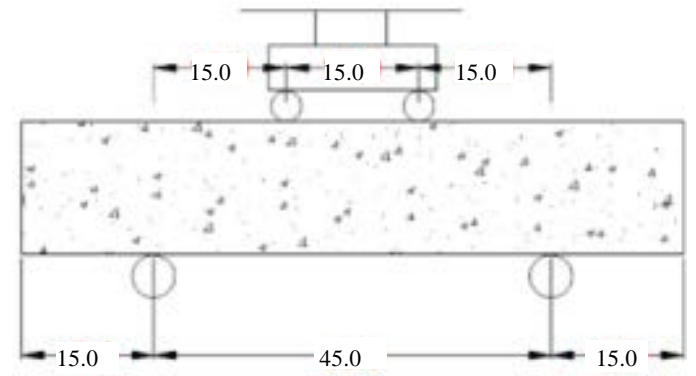

Fig. 4: Illustration of the experimental set up

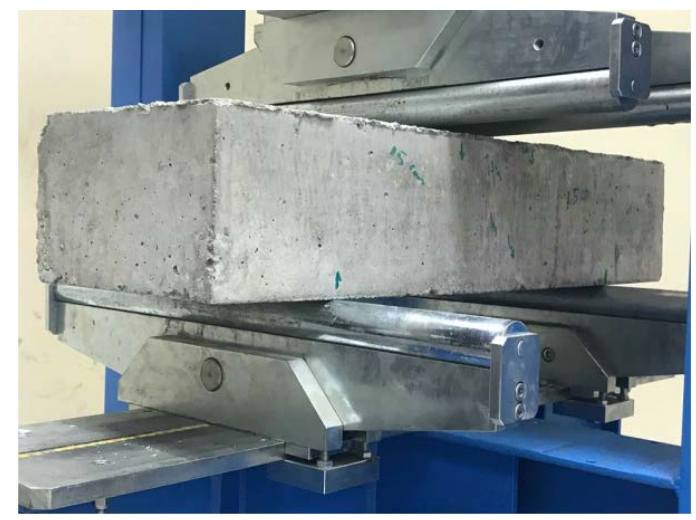

Fig. 5: Ribbed slab experimental set up

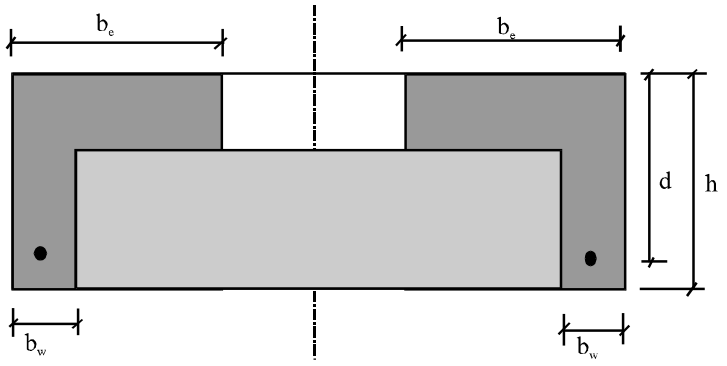

Fig. 6: Slab cross-section

bottom of the slab. This type of failure is tension control failure where the steel bars yield. Figure 6 shows a section in the slab. According to the American Concrete Institute (ACI), the width of flange, $b_{e}$ is a function of the web width, $b_{w s}$ clear transverse span, thickness of the flange, $h_{f}$ and the longitudinal span length, 1 (Anonymous, 2014).

The design is based on having the compressive block model, a to be less than or equal to the thickness of the flange, $h_{\mathrm{f}}$ From section equilibrium, the following Eq. 2 can be generated:

$$
\mathrm{a}=\frac{\mathrm{A}_{\mathrm{s}} \mathrm{f}_{\mathrm{y}}}{0.85 \mathrm{f}^{\prime}{ }_{\mathrm{c}} \mathrm{b}_{\mathrm{e}}}
$$


Where:

$\mathrm{A}_{\mathrm{s}}=$ Area of steel reinforcement

$\mathrm{f}_{\mathrm{c}}{ }_{\mathrm{c}}=$ Concrete compressive strength

$\mathrm{f}_{\mathrm{y}}=$ Steel tensile strength

The flexural moment capacity, $\mathrm{M}_{\mathrm{n}}$ can be estimated by the following Eq. 2:

$$
\mathrm{M}_{\mathrm{n}}=\mathrm{A}_{\mathrm{s}} \mathrm{f}_{\mathrm{y}}\left(\mathrm{d}-\frac{\mathrm{a}}{2}\right)
$$

\section{RESULTS AND DISCUSSION}

Figure 7 shows the effect of the amount of the fiber used in this study on the compressive strength of concrete. The increase in the amount of fiber increases the concrete compressive strength. Excess amount of fiber will make the fiber in effective due to lumping and mixing difficulty. For practical reasons the weight of fiber used in this study is $0.057 \%$ of the cement weight.

Figure 8 shows the effect of the maximum applied load on the spacing between the ribs. This figure shows that the strength of the slab decreases with the increase in the ribs spacing. This decrease is almost of linear relationship. Figure 9 shows the effect of the ribs spacing on the strength to weight ratio. The strength to weight ratio is not quite sensitive to the ribs spacing. Slight decrease in the strength to weight ratio is observed as the ribs spacing increases. This decrease in the strength to weight ratio becomes significant after the ribs spacing of $20 \mathrm{~cm}$ (8 inch).

The material cost is also considered in this study. This cost is mainly dependent on the volume of the concrete used and the weight of the steel reinforcement used. The price per unit volume of concrete is taken as the average price in the USA in the year 2018 which is taken to be $\$ 90 / \mathrm{m}^{3}$ or $\$ 2.55 / \mathrm{ft}^{3}$. The steel reinforced price is calculated based on the tonnage weight of the steel which is taken to be $\$ 0.3$ per pound or $\$ 0.66 / \mathrm{kg}$. Figure 10 shows the relationship between the material cost per unit width of the slab and the strength of the slab per unit width. The material cost increases with the increase in the strength. It is also noted from that figure that this increase in material cost becomes mild at the ribs spacing of $20 \mathrm{~cm}$ (8 inch).

Figure 11 shows the location of the flexural crack in the tested slabs. It is noted that the flexural crack is more or less at the middle of the slab. Figure 12 shows the modes of failure of each ribbed slab tested.

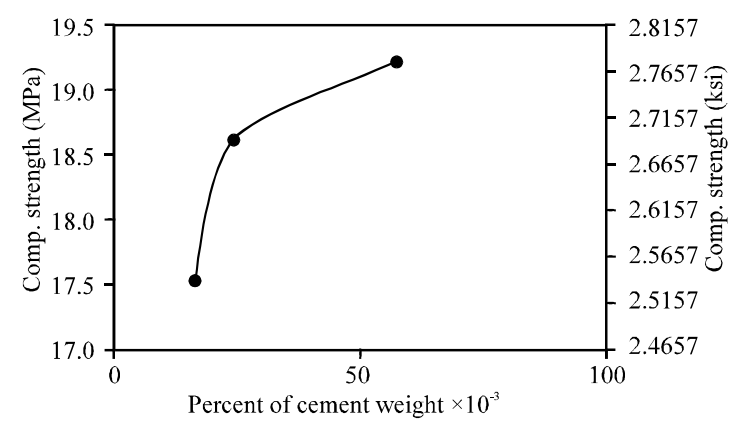

Fig. 7: Effect of fiber on the concrete compressive strength

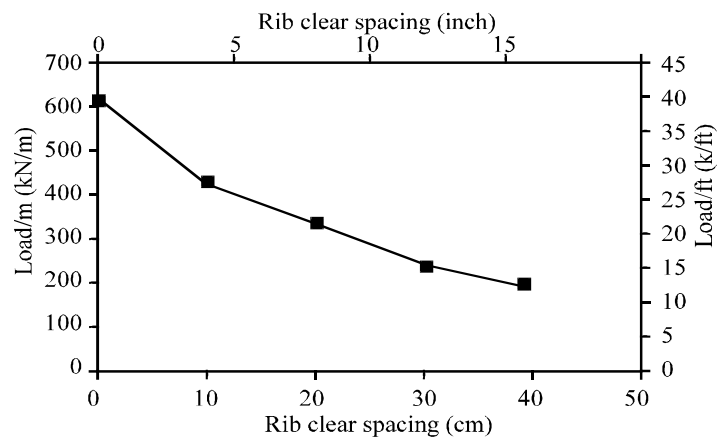

Fig. 8: Relationship between the maximum applied load per unit width and the ribs spacing

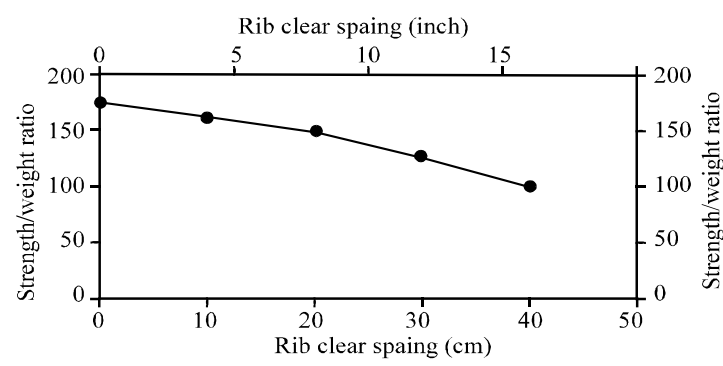

Fig. 9: Effect of the ribs spacing on the strength to weight ratio

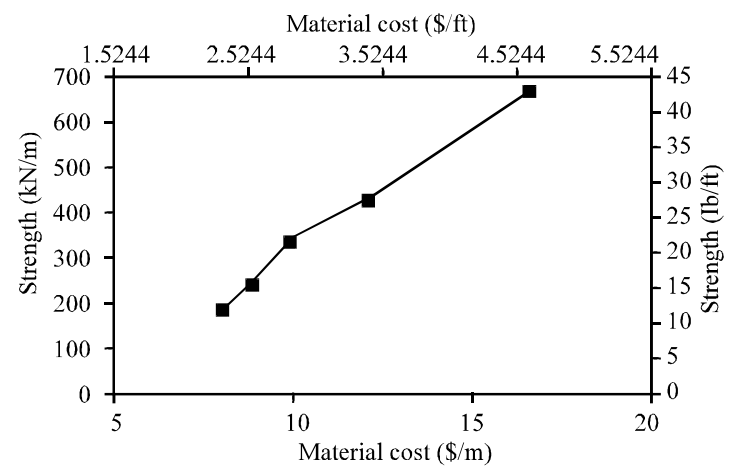

Fig. 10: Relationship between material cost and slab strength per unit width 


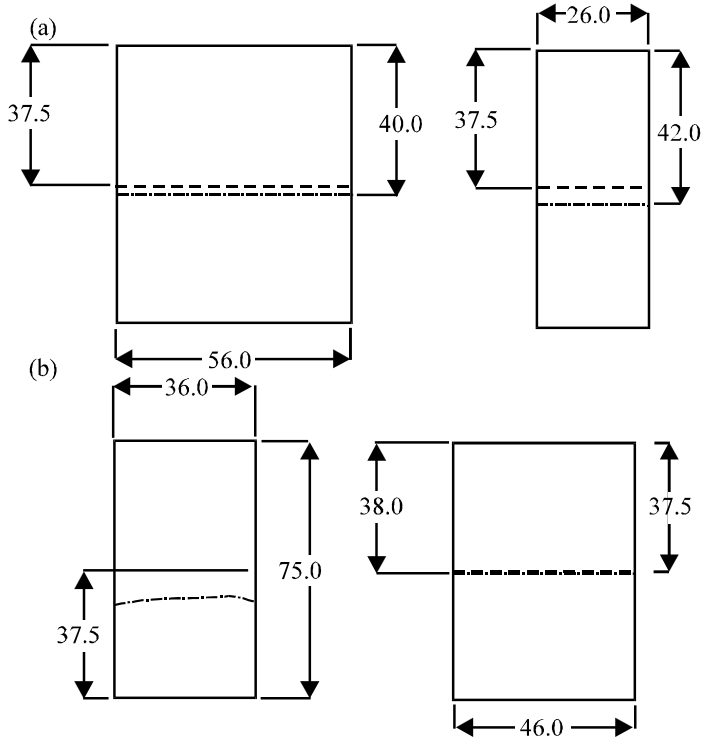

Fig. 11: Location of the flexural crack in the tested ribbed slabs

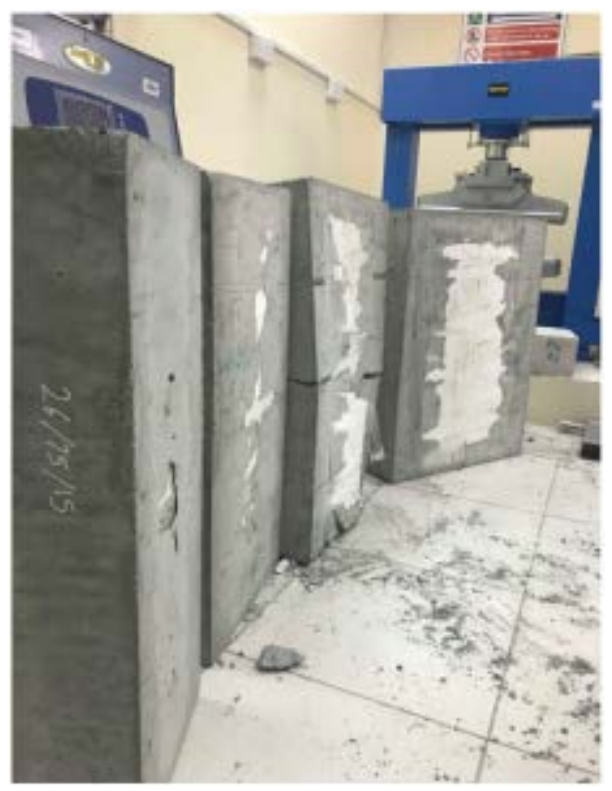

Fig. 12: Ribbed slabs of variable width after failure

\section{CONCLUSION}

The ribbed slabs are proven to be effective slabs loaded mainly by surface loads. The dead weight of the ribbed slabs can be reduced substantial by using light weigh fillers between the ribs. The flexural strength of the one way reinforced concrete slabs increases with the decrease in the rib spacing. Also, the strength of these slabs increases with the increase in the material cost of the slabs. There is a slight decrease in the strength to weigh ratio with the increase in the ribs spacing. It is noted that the ribs spacing of $20 \mathrm{~cm}(8 \mathrm{inch})$ produced balanced tradeoff between strength and cost.

\section{REFERENCES}

Abejide, O. and C. Konitufe, 2015. Optimization of flexural prediction for ribbed floors in bending, shear and deflection. Am. J. Eng. Res., 4: 60-71.

Al-Nasra, M. and L.R. Wang, 1994. Parametric study of slab-on-grade problems due to initial warping and point loads. Struct. J., 91: 198-210.

Al-Nasra, M. and M. Daoud, 2015. Investigating the transitional state between circular plates and shallow spherical shells. Am. J. Eng. Res., 4: 72-78.

Al-Nasra, M. and M. Daoud, 2016. Effect of the aspect ratio on the transitional structural behavior between plates and shells. Intl. J. Appl. Eng. Res., 11: 10634-10639.

Al-Nasra, M., A. Najmi and I. Duweib, 2013. Effective use of space swimmer bars in reinforced concrete flat slabs. Intl. J. Eng. Sci. Res. Technol., 2: 195-201.

Al-Nasra, M.M., I.A. Duweib and A.S. Najmi, 1926. The use of pyramid swimmer bars as punching shear reinforcement in reinforced concrete flat slabs. J. Civ. Eng. Res., 3: 75-80.

Anonymous, 2014. Building code requirements for structural concrete (ACI 318M-14) and commentary. American Concrete Institute, Michigan, USA.

Galeb, A.C. and Z.F. Atiyah, 2011. Optimum design of reinforced concrete waffle slabs. Intl. J. Civ. Struct. Eng., 1: 862-880.

Rahman, F.A., A.A. Bakar, M.H.M. Hashim and H. Ahmad, 2017. Flexural performance of Steel Fiber Reinforced Concrete (SFRC) ribbed slab with various topping thicknesses. Proceedings of the $3 \mathrm{rd}$ International Conference on Construction and Building Engineering (ICONBUILD) Vol. 1903, August 14-17, 2017, AIP Publishing, Palembang, Indonesia, ISBN: 978-0-7354-1591-1, pp: 020013-1020013-6. 